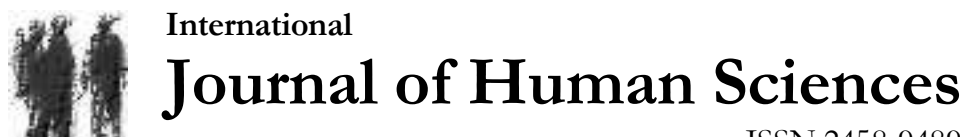 \\ ISSN:2458-9489
}

Volume 18 Issue 4 Year: 2021

\section{Cultural transformation and translation}

\section{Kültürel dönüşüm ve çeviri olgusu}

\section{İskender Güneş ${ }^{1}$}

\begin{abstract}
Along with the cultural transformation and renewal process of the world, the need for reinterpretation in the field of translation has come to the fore. The increase in cultural activities and transformations has led to the emergence of new dimensions in the communication and interaction of societies. Especially after the second half of the 20th century, the rapid social, economic and cultural mobility, which started to gain a new dimension, intensified the cultural interaction, and also led to the production of many written and oral works in this field. The dimensions of cultural data transfer, including these produced works, have begun to increase. The most important role in the transfer of these data between cultures and languages is the translation institution, which has the importance of a cultural carrier beyond being a purely linguistic transmission tool. In this study, firstly, the concept of culture is examined within the general framework. Following this, the concept of translation and its relationship with the phenomenon of culture are discussed. In the study, an answer is sought to the question of what exactly is understood from the concept of culture. Finally, the complementarity effect of the concepts of translation and culture is emphasized.
\end{abstract}

Özet

Dünyanın geçirdiği kültürel dönüşüm ve yenilenme süreci ile çeviri sürecini yeniden yorumlanma ihtiyac1 ön plana çıkmaya başlamıştır. Kültürel faaliyetlerin ve dönüşümlerin yaşanmasındaki artış toplumların iletişim ve etkilişimde de yeni boyutların ortaya çıkmasına neden olmuştur. Özellikle 20. yüzyllın ikinci yarısından sonra yaşanmaya başlayan hızlı sosyal, ekonomik ve kültürel hareketlilik yeni bir boyut kazanmaya başlayan kültürel etkileşimin yoğunlaşmasını sağlarken bu alanda birçok yazıll ve sözlü eserin üretilmesine de yol açmıstır. Üretilen bu eserler de dahil olmak üzere kültürel veri transferinin boyutları da artmaya başlamıştır. Bu verilerin kültürler ve diller arasinda transferindeki en önemli rol ise salt dilsel aktarım aracı olmasından öte kültürel bir taşyıc1lik önemi de haiz olan çeviri müssesesindedir. Bu çalışmada ilk olarak kültür kavramı genel çerçeve içerisinde ele alınarak irdelenmektedir. Bunu müteakiben ise çeviri kavramı ve kültür olgusu ile olan ilişkisi ele alınmaktadır. Çalışmada kültür kavramından tam olarak neyin anlaşılmakta olduğu sorusuna cevap aranmaktadır. Nihai olarak ise çeviri ve kültür kavramlarının birbirine yaptuğ tamamlayıcılık etkisi üzerinde durulmaktadır.

Anahtar Kelimeler: Kültür, Çeviri, Sosyal, Dil

Keywords: Culture, Translation, Social, Language.

Extended English summary is at the end of this document)

\footnotetext{
1 Sakarya Üniversitesi, Sosyal Bilimler Enstitüsü Çeviribilim Bölümü Doktora Programı Öğrencisi, iskender34gunes@gmail.com (D) Orcid ID: 0000-0003-4829-3220
} 


\section{Giriş}

Çevirinin ortaya koyduğu çalışmalar öncelikle sistemsel açıdan ele alınarak yapılacak çalışmalar üzerinden yol alındığı takdirde ortaya konulacak olan çeviri ürünlerinin niteliği de tam olarak değerlendirilebilecektir. Bunun yanında; “Geetz’e göre kültür, paylaşılan anlamlar sistemidir. Hall ise kültürü iletişim olarak tanımlar. Fiske, kültürü sosyal deneyimin sürekli anlam> ve sosyal deneyimden sürekli anlam üretme süreci olarak aktarır”. (Erdoğan, 2005, s.136.). Aynı zamanda diğer bilim dallarını etkileme ve bu alandan yapılan çalışmaları destekleme gücüne sahip olan çevirinin bu özelliğine özellikle vurgu yapan Hönig; "Bugün bunca teşvik edilen uluslararasındaki diyaloğun, galiba en kalıcısı Felsefe ve Edebiyatlarının çevirisi sağlar. Hangi dilde yazılmıssa yazılsın, insanlığın malı olan yeniden üretme ürünü yapıtlar, ancak çeviri sayesinde gerçekten insanlığın malı olabiliyor"“(Hönig 1982, s.33-34) ifadeleriyle destekleyerek çeviri faaliyetlerinin diğer disiplinlere sunduğu katkıyı tanımlamaktadır. Çevirinin tek başına faaliyet gösteren bir eylem olmadığını vurgulayan Chesterman, çevirinin dilsel ve edimsel bir uygulamanın öteside tarih, kültür, ekonomi, filoloji, antropoloji, coğrafya, politika, psikoloji ve bilişim alanlarını da kapsayan bir yapı halinde semantik ve sosyal düzlemde çeşitli araştırma sahalarını da sürece dahil ettiğini belirtir. (Chesterman, 2012:6-27). Kaindl'e göre çevirinin kültürlerarası bir olgu olmasının ötesinde, bir toplumun içindeki sosyal alanların marifetiyle geliştiği aktarılmaktadır. Bu görüşe göre sosyal bakış açısının kültür esaslı bakışa göre örtük biçimde yer aldığı belirtilmektedir. Çeviri alanındaki sosyolojik yaklaşım ise 90’lı yıllardan ardından kültür esaslı bakış açısı yaklaşımlarının tamamlayıcı öğesi biçiminde değerlendirilmektedir. Theo Hermans'ın (Hermans, 1996, Aktaran: Klaus Kaindi, 1999, aktaran: Arı, 2014, s.21.) görüşüne göre de çeviri kültürel olmanın ötesinde sosyal olarak değerlendirilmesi gerek bir faaliyet olarak ön plana çıkmaktadır. Chesterman (Kaindi,1999, s.124 aktaran: Ar1, 2014, s.21.) çeviriye dair ortaya koyduğu sosyolojik yaklaşım üzerinden insanların odak noktasının dikkate alındığını belirtmiştir. Aynı zamanda üç köprü kavramı biçiminde aktardığı kavramla diğer kavramlar arsında belirli bir bağlantı da kurmaktadır.

\section{Yöntem}

Kültürel dönüşüm ve çeviri olgusunu inceleyen bu makalenin temel amacı çevirinin kültürel dönüşüm ile ilgili yaşadığı süreci anlamaktır. Bu amaç doğrultusunda alan yazın incelenerek çeviri olgusu ve kültürel dönüşüm incelenmiştir. Bu amaca dönük tarama modeli çalışma yöntemi biçiminde belirlenmiştir.Tarama yöntemi ile yapılan araştırmalar gerçekleştirilirken konuların doğrudan incelenebildiği gibi önceden kaydedilmiş çeşitli kaynaklara da başvurulmuştur. Araştırmada tarama modeline uygun biçimde veri tabanları olan EBSCO, ERIC, Google Scholar, TR Dizin, Dergipark ve Yök Tez merkezi kullanılarak araştırma amacına hizmet eden dokümanlar taranmıştır. Edinilen bilgilerin getirdiği veriler sistematik bir şekilde incelenerek araştırmanın amacı doğrultusunda sınırlandırılmıştır. Yapılan literatür taraması ile makalenin çalışma alanı çeviri ve kültür olgusu ile ilgili konularla sınırlandırılmıştır. Çalışmanın sınırlılıkları çerçevesinde alanda önemli katkıları olan uzmanların görüşlerine yer verilmiştir.

\section{Kültür Kavramı}

Kültür kavramı Batıdaki aydınlanma felsefesinden kalmış bir miras olarak kabul edilir. Bu kavram ilk çağlardan günümüze kadar yazılı miras olan "kültür" biçiminde de tanımlanabilmektedir. Antropolojik görüsse göre kültür, "bilgilerin, inançların, sanatların, değerlerin, kuralların, örf ve âdetlerin, toplumun üyesi olan insan tarafindan sonradan kazanılmış bütün kapasite ve alışkanlıkların tümü” biçiminde ifade edilmektedir. Bu görüşün etkilerinin günümüzde de sürdüğ̈u görülmektedir. (Journet, 2009, s.15-16.)

Kültürün, kişilerin davranışlanı ile ilgili bilgi verdiği ve bu davranışların da yansımasıyla soyut görüşlerin yanısıra, değerlerin ve dünyaya dönük algıların bütünü olduğu da düşünülmektedir. Aynı zamanda kültürün, bir toplumun üyeleri tarafindan paylaşılarak o 
toplumun mensuplarınca da kabul gören hareket içerisinde bulunmaya yol açtı̆̆ da belirtilmektedir. Biyolojik açından ise kültürün önceki nesillerden miras olmadığı bilakis sonradan öğrenilen bir mefhum halinde farklı parçalarının bütüncül biçimde faaliyet gösterdiği bir değer olduğu aktarılmaktadır." (Haviland. A., ve L. Prinss, v.d. 2008, s.102). "Kişinin, toplumun bir üyesi olarak kazandığı bilgi, inanç, sanat, hukuk, ahlak, adet, gelenek, alışkanlık ve yetenekierin karmaşık bütünü" olarak tanımlar. Tylor'ın kültür tanımından günümüze kültür tanımları hızla çoğalmış ve çeşitlenmiştir. 1950'lerde Kuzey Amerikalı antropologlar A.l.Kroeber ve Clyde Kluckhohn birlikte bir akademik alanyazın taraması yaptılar ve yüze yakın kültür tanımına ulaştılar." Şeklindeki görüşü ile Burnett Tylor ise 187l'deki eserlerinde kültürü tanımlamaktadır (Haviland. A., ve L. Prinss, v.d. 2008, s.103). "Yaşanmış pratikler üzerinden bir toplumun hayatiyetindeki şartların deneyimlenmesi, tabir edilmesi ve ifade bulması anlamında görev üstlenen pratik ideolojiler" ifadesiyle kültürü tanımlayan Stuart Hall kültürün tecrübeye dayanan yanı üzerinde durmaktadır (Hall, 1982, s.7). Giddens ise kültürün sosyal boyutunu ele alarak toplumu meydana getiren fertlerin değerlerini, normlanını, maddi anlamda ortaya koydukları eserleri, yaşam biçimlerini, giyim, dinî tören, evlilik adetleri, aile, eğlence gibi alanlardaki sosyal özellikleri üzerinde durmaktadır (Giddens, 2005, s.31). Smith’in üzerinde durduğu kültürel alanın yapısı ise ortak kültürel değerlerin öğeleri olan; yaşam tarzı, inançlar, stiller, değerler ve sembolleri değerlendirmeye alınması biçimindedir.

Clyde Kluckhohn’un görüşüne göre kültür 11 maddelik bir şemada gösterilebilir. Buna göre;

\section{Tablo 1: Clyde Kluckhohn'a Göre Kültür}

\begin{tabular}{|c|}
\hline 1) "bir halkın yaşam biçiminin tamamı" \\
\hline 2) "bireyin kendi grubundan elde ettiği toplumsal kalıt" \\
\hline 3) "bir düşünme, hissetme ve inanma yolu" \\
\hline 4) "davranıştan bir soyutlama" \\
\hline 5) "antropolog açısından bir grup insanın gerçekte davranış biçimleri konusunda bir kuram" \\
\hline 6) "toplu halde öğrenme için bir depo" \\
\hline 7) "yeniden su yüzüne çıkan sorunlar karşısında bir ölçünleştirilmiş yönelimler seti" \\
\hline 8) "öğrenilmiş davranış" \\
\hline 9) "davranışın düzgüsel düzenlenişi için bir mekanizma" \\
\hline 10) "hem dış çevreye hem de diğer insanlara uyum sağlamak için bir teknikler seti" \\
\hline 11) "bir tarih çökeltisi" \\
\hline
\end{tabular}

Kaynak: Geertz, 2010, s.18-19Kültürün dışa dönük yüzünü ele alan Strauss ise görüşünü dile getirirken Taylor'dan aktarım yapmaktadır. Buna göre; “Tylor'a göre kültür, araçları, kurumları, inançları, gelenekleri ve doğal olarak dili kapsayan karmaşık bir bütündür... Dili kültürün bir koşulu olarak da ele alabiliriz, çünkü birey bağlı olduğu kültürü dil aracıllğıyla tanır ve içselleştirir" ifadesini kullanmaktadır. (Strauss, C.L, 2012, s.107)

Aksoy tarafindan ise kültür olgusunun gelişimi ile ilgili çeviri kavramina vurgu yapılmaktadır. Bu alada çalışan önemli akademisyenler de gündeme getirilerek çevirinin kültür sürecine katkısında metin özgünlüğ̈̈ne dair bir vurgu yapıldığ1 görülmektedir. Buna göre Aksoy'un ifadesi; "Kültür olgusunun gelişmesinde önemli bir rolü olan çeviri, Türkiye'de ve batı dünyasında bu bakımdan değerlendirilirken dil araştırmaları ve dil biliminde olan ilerleme sonrasında Wolfram Wilss, Albrecht Neubert, Haps J. Vermeer gibi Alman çeviribilimciler, Jacobson, George Stenier gibi İngiliz dilbilimciler ve dilbilim alanında benzer görüşleri paylaşan uzmanlar tarafından çeviri süreci dilbilimsel olgu yaklaşımı biçiminde incelenmiştir. Bu bakış açısı çeviri sürecinde özgün metne sadakati daha fazla ön plana almaktadır” biçimindedir (Aksoy, 2000, s.58). 


\section{2. Çeviri Olgusu}

Çeviri ile ilgili olarak Finlandiyalı çeviribilimci Holz-Mäntäri’nin tanımı dikkat çekmektedir. Bu görüşe göre çeviri hakkında; "bir amaç doğrultusunda gerçekleştirilen bir eylem türüdür"denilmektedir (Maenttaeri, 1984, s.95). Kültürün ve bilimin gelişmesinde önemli katkıları olan çeviri faaliyetleri yapısal ve biçimsel olarak farklı bilim insanları tarafından çeşitli açılardan da ele alınarak irdelenmektedir. Kültürel bir değer taşıması açısından da önemi haiz olan bu sistemlerin sağlayacağ1 üretim de kendi içinde bir paradigma içermektedir. Buna göre Mutlu; "Çeviri, çevirmen eyleminden dolayı bir sistem ya da kapalı bir sistem değildir. Çeviri, çeviri olayından, çevirinin kendi bütünsel yapısal toplumsal sisteminden dolayı kapalı bir sistemdir. Kendini bu sosyal sistemin iletişimsel açıdan yllar ve farklı toplumlar süresince yeniden üretmesinden dolayı bir anlamda çeviri eylemi kuramında, çevirinin bireyselliği ve çevirmenin bireysel rolünü geride bırakan bir yeni paradigmadan söz edilmektedir. Bu paradigmada çeviri eylemi, çevirmenin geçici kararları değil, geçici olan içinde değişmez olan ve sistemle benzerlik gösteren, o çeviri sürecini genel çeviri sistemi içinde benzer değerlendirecek özelliklerin çevirinin autopoietik sistemini oluşturabileceğini ifade eder" görüşü ile çeviri sürecinin sistem açısından autopoietik bir yapıya sahip olduğunu, bu durumun çevirinin ve çevirmenin bireyselliğin dışına çıtı̆̆ını da ifade ederek belirtmektedir (Mutlu, 2019, s.19).

Çeviri kavramının disiplinlerarası yapısına değinen Hönig ise Çeviribilimin bütünleştirici yapısına vurgu yaparak onu bir bilim olarak tanımlamaktadır. Bu görüşe göre çeviribilim ruhbilim, toplumbilim, kültürbilim, dilbilim ve yazınbilim olarak adlandırılan diğer bilim dallarını da kapsayan bir yapıdadır. İlerleyen süreçte ise çeviri mevcut bilimsel disiplinler arasında kendisine bir yer edinmiş ve bağımsız bir disiplin olararak ortaya çıkmıştır. Konu ile ilgili olarak Mutlu; "Çevirinin kendi doğasından ortaya çıkan çalışmaların, özellikle çeviri faaliyetini pratik eylem olarak gerçekleştiren bilim insanları tarafından ele alınmasıyla birlikte bir çeviribilimden ve çevirinin bağımsız bir disiplin olmasından söz edilmeye başlanmıştır. Bunun devamı olarak çeviri tanımlarında da radikal değişiklikler meydana gelmiş ve çeviri artık bir süreç, bir anlama eylemi ve bir kültürel/toplumsal faaliyet olarak tanımlanmaya başlanmışır’ ifadesini kullanmaktadır. (Mutlu, 2019, s.27).

Çeviri süreçlerinde tartışlan bir diğer konu ise çeviri yapılırken geliştirilen stratejiler olmaktadır. Eserin çevirinin yapılacağı hedef kültürü mü yoksa kendi özgünlüğünü mü öncelmesi gerektiği anlamında da devam eden tartışmalar bulunmaktadır. Konu ile ilgili olarak Romalı çevirmenler tarafindan ortaya atılan "orjinali aşma" ve "erek kültürü gözetme” biçiminde görülen bu olgu toplumsal toplumsal beklentilerin çeviri üzerindeki duruşunu da ortaya koymaktadır. Vermeer konuya dair Roma çeviri geleneği içerisinde metinsel tür anlamında sürecin bilimsel alanın olabildiğince kelimesi kelimesine, edebiyat sahasında ise kaynak metninin ötesine ulaşma şeklinde gelişirken retorik alanında ise ulaşılması amaçlanmakta olan okuyucuya tesir etme biçiminde türlere ayrılan çeviri yaklaşımlarının varlığından bahsetmektedir (Vermeer, 1992:197 aktaran: Tosun, s.56). Bu süreçte çevir ile ilgili öenmli araştırmaları olan bilim insanlarının evir faliyetini tanımlama ile ilgili gayretleri ortadayken çeviri sürecinin kaynak ve erek metin bağlamında da tartışıldığı ifade edilmektedir. Bu göre Mutlu; "Çeviri araştırmacıları, çeviri olgusunu araştırma ve çeviriye ilişkin kuramlar oluşturma çabalanı içindeyken, çeviriye iki farklı açıdan yaklaşmış olduklarını gözlemleyebiliyoruz. Birinci yaklaşım, çeviriyi kaynak metne bağlı kalarak üretme çabası, yani kaynak odaklı bir çeviri yaklaşımı olarak göstermek, ikinci çeviri anlayışı ise, çeviri ürününü erek kültür içerisinde üstleneceği işleve göre üretmek, yani çeviriyi erek odaklı bir yaklaşımla ele almak olmuştur” ifadelerini kullanmaktadır. (Mutlu, 2019, s.39). Bu noktada Luther'in çeviriye dair kullandığı ifadeyi hatırlamak süreci kavramak adına yerinde olacaktır. Çeviri ile ilgili; "rem tene, verba sequentur" (sen konuyu kavra, cümleler kendiliğinden ortaya çıkar) ifadesini kullanan Luther çevirmen ve metin arasında kurulması gereken bir yakınlık olduğuna dikkat çekmek istemektedir. Bu yakınlık kurulduğu takdirde ise erek metinde ve kültürde hedeflenen etkinin sağlanması çeviriden beklenen etkinin oluşmasına da katkı sunacaktır 
(Stolze, 2001: 39 aktaran: Tosun, s.59). Esasında 'Sendbrief vom Dolmetschen' adını taşıyan eseri Luther'in, kendi işlevsel çeviri yöntemini anlattı̆̆ı bir eser özelliği de taşımaktadır.

\section{3. Çeviri ve Kültür İlişkisi}

Çeviri sürecinde esas hedefin kültürel kodların uygun ve yerinde aktarımı olduğu düşüncesinde olan alan uzmanlarının görüşlerinden de yola çıkılarak H.J. Störig’in kültür ve çeviri arasındaki görüşüne dikkat çekmek yerinde olacaktır. Störig konuyu tanımlarken; "çevirinin, iki farklı kültürün bir arada yaşaması, bir kültürün diğer kültür üzerinde daha etkili olması ve iki kültür arasında bulunan farklılıklardan oluşan durumlarda ortaya çıkan eylem olduğu fikrini ortaya atmaktadır (Störig, 1993).

Bunun yanında G. Mounin tarafında ortaya atılan görüş ise çeviri ve kültür ilişkisine dair: "Bir dili çevirmek için iki koşulu yerine getirmek gerekmektedir, tek başına biri yeterli olamaz, yabanc1 dili iyi öğrenme, o dili kullanan topluluğun kültürünü bilmekle olur. Hiçbir çeviri bu iki koşul yerine getirilmedikçe yeterli sayılamaz" biçimindeki ifadelerle süreci yorumlamaktadır. (Georges, 1963, s.236). Bu noktada çeviriyi betimleyici bir bakış açısıyla ele alan yaklaşım süreci ürün, süreç ve erek kültürdeki işlev biçiminde değerlendirmeye tabi tutmaktadır. Betimleyici kuram esas olarak aşağıdaki gibi ele alınmaktadır (Holmes, 1998, s.95);1.

"Çeviri süreci kuramı; bir kişinin bir şeyi çevirmek istemesi durumunda neleri gerçekleştireceğine ilişkin karar verme süreci kuramı,

2. Çeviri ürünü kuramı; Var olan çevirilerin betimlenmesi sürecidir. Yani çevrilmiş olan metni, metin olarak karakterize eden unsurlara ilisskin kuramdır.

3. Çeviri işlevi kuramı; Çevirinin alımlayıcı kültürde nasıl bir etki bıraktığı ile ilgilidir. Belli bir dönemde hangi metinlerin çevrildiği / çevrilmediği ve çevrilen metinlerin yarattı̆̆ etki" biçiminde tanımlanmaktadır.

Ateşman ise çevirinin salt bir metinsel kelime değişimi olmaktan çok kültürel transferler barındıran bir yapıya sahip olduğunu belirterek; "Hans J. Vermeer'in görüşlerine dayanarak, çeviriyi bir kültür aktarımı olarak görürken Humboldt'un dil ile kültür arasındaki klasik ilişkisinden yola çıkıyorum. Dil, o dili konuşan insanların dünyaya bakış, o dünyayı kavrayış biçimi aynı zamanda. Yani dil dediğimiz şey, bir grup insanı ya da toplumu diğerlerinden ayırt edici özelliklerin toplamı anlamına gelen kültürün bir parçası" görüşünü ortaya koymaktadır. (Ateşman, 2001, s.31). Cömert'e göre çeviri faaliyeti alt ve üst kültürler arasında veya bir kültürün kendi içinde gerçekleşen bir süreç halinde gelişirken diller arasında de geçmiş ve gelecek arasında köprü rolü üstlendiği görülmektedir. Aynı zamanda, kültürün geleceğe bakan bir yönü olması nedeniyle "insanlık için bir eser olacak biçimde günümüze taşınması ve eşzamanlı olarak milli kültürler arasında geçişkenliğin sağlanması"nın beklendiği ifade edilmektedir. Sürecin bu bakımdan "kültürel öğeler arasında etkileşim ve yenileyici dönüşüm" ile yenilenme içine girdiği de anlaşılmaktadır (Cömert, 1978, s.26).

Vermeer ise çeviriyi; çevirmenin içinde bulunduğu milletin (para-), çevirmenin kendi dahil toplumsal grubun (dia-) ve çevirmenin etrafindaki faktörlerden oluşan kültürün (idio-) alanı ile ilişkilendirerek bu süreci normlar, değerler ve kültürel anlaşmalar biçiminde değerlendirmektedir (Vermeer, 1996, s. 93). Prunc çeviriyi tanımlarken kullandığ "gelenekselleştirilmiş dil içi ve kültürler ötesi etkileşim olarak" ifadesiyle çeviribilim için konu alanının sınırı çizme gayretindedir. Çeviribilimin prototipik sahasına dair "eşdeğerlik beklentilerine" cevap ararken ise mevcut eğilimleri sınıflandrmaktadır. Bu sınıflandırmayı yaparken marjinal ve geleneksel biçiminde bir tasnife girişmektedir. Kültürel uzlaşmaların modelleştirilmesi anlamında ise Fransız sosyolog Pierre Bourdieu'nün görüşlerine dikkat çekmektedir (Bourdieu, 1987). Çeviri süreci esnasında karşılaşılan bir sorun olarak kültürü ele alan Ateşman bu durumu dilsel bir sorun olarak görmeyerek konuya farklı bir yaklaşım getirmektedir. Ateşman; "Bu bağlamda ortaya çıkan sorunların bir kısmı kültürel sorunlar olarak ele alınabilir. Aslında kültürel sorunları dilsel sorunlardan ayırmak oldukça güçtür. Dili de kültürün bir parçası olarak gördügümüze göre, her 
dilsel sorun aynı zamanda bir kültürel sorun olarak da sınıflandırılabilir. Ama ben doğrudan dilsel olmayan, yani iki dil arasındaki yapısal farklılıktan kaynaklanmayan sorunları kültürel sorun olarak görmek gerektiğini düşünüyorum.” ifadeleriyle konuya açıklık getirmektedir (Ateşman, 2001, s.32). Even-Zohar ve Toury de çeviri sürecini hedef kültüre ait bir ürün olarak yorumlayarak alana bu anlamda katkı sunmaktadır. Bu noktada Yücel çeviri açısından hedef dile dair işlevsellik bakış açısına göre her iki görüşe de dikkat çekmektedir. Süreç incelendiğinde çevirinin sosyokültürel ve siyasal açıdan incelenmesinin önemine dair yapılan vurgu dikkat çekmektedir. (Yücel, 2007, s.50.)

Çeviri eserlerin özgün olmasını önemseyen Cicero ise edebi çevirilerde serbest bir tavır takınmaktadır. Yunanlıların eserlerini tercüme ederken Roma kültürünü önemseyerek çeviri yapar. Vermeer'e göre ise edebi eser terümesi bu eserin orijinal halini yazmaktan daha zordur. Bu göre Vermeer Cicero kuramı çerçevesinde Vermeer şu tesbitlerde bulunur:

1) Yazarların ve şairlerin sahip oldukları bağımsız yazı yazma özellikleri nedeniyle bir yazarın yazılı biçimde söyleneni yeniden söylemesinin zorluğu, bu tarz yazarların elinden çıkan eserlerin çevirisini zorlaştırmaktadır.

2) Normal şartlarda bir çevirmenin sözcügü sözcügüne yaptığ1 çeviri çalışmasını sanatç1 özelliğine sahip bir çevirmen daha rahat hareket ederek yapar. Bu görüşe göre sanatçı çevirmen kimliği daha fazla öne çıkmaktadır (Vermeer, 1992:17 aktaran: Tosun, s.58).

Bunun yanında Arı'nın kültürel sembolleri inceleyen çalışması pozitivist bilim anlayışına dair verilen bilgilere atıfta bulunarak bu bakış açısının kültürü de safdış bırakma düşüncesinde olduğunu ifade etmektedir. Bu bakış açısının soyut bir ilisski sonucunda dünyayla kurulan irtibatla ilgili olduğu belirtilerek bilimsel anlayışın aksine farklı bir bakış açısından dünya bakışı oluşturulduğu aktarılmaktadır. Aynı zamanda Arı Ernst Cassier’in Kantçı dünya görüşüne karşı, "kültürel semboller kuramı" ile bakış açısını ortaya koyduğunu belirtmektedir. Arı, Cassier'in, insanın dünyaya bakışının kültürel sembollerin aktarımı ile devam ettiğini belirtttiğini aktarmaktadır. Pierre Bourdieu'nun ise Cassier'in kültürel semboller kuramını, sembolik formlar kuramı olarak kitaplaştırdığı ve bir toplum üzerinde sanatın ve kültürel sembollerin etkin rol oynadığı aktarılmaktadır. Bourdieu'nun Habitus kuramı ve Alan kuramı ise bu noktada dikkate alınmaktadır. Bu bakış açısının kültürel sembollerin değerlerini de irdelendiği belirtilmektedir. (Arı, 2016, s.6.). Holz-Maenttaeri her eylemin belirli bir amaca yönelik olarak planlı bir biçimde yapıldığı düşüncesini taşımaktadır. Bu bakış açısının açık bir dizge biçiminde ifade edildiği görülmektedir. Dizgenin durağan değil bilakis hareketli bir biçimde olduğu gözlenmektedir. Bu görüsse göre kaynak metin kapalı bir dizge biçimindedir. Çeviri ise bu dizgenin hareket geçerek yeni bir dizgeye dönüşmesinin önünü açmaktadır. Bu durumda ise yaşanan dönüşüm sayesinde metnin içeriğinin bir dilden diğer bir dile aktarılmasının ötesinde kültürler arasında bir akış süreci görülmektedir. Bu akışta ise farklı kültürler arasında yeni bir işlevle yapılanma yapıldığı görülmektedir. (Maenttaeri, 1984, s.28)

Bunun yanında çeviri süreçlerinin ve kendi ürünlerinin hedef kültürün değişiminde rol aldıkları da görülmektedir. Bu itibarla (Toury, 1980, s.27) çevirinin çıkış noktası hedef kültürün "örnek aldığı” değerlerinin varlığına katkı sunabilmektedir. Bu bakış açısına göre çevirilerin hedef kültürün etkisiyle şekillendiği görülmektedir (Störig, 1963., s.185). Bu durumun en öneli süreçlerinden biri 1980'li yıllarda “kültürel dönüşüm”le (cultural turn) terimin çeviri alana giriş yapması olarak görülmektedir. Bu terim kullanıma 1990 yllında basılan "Translation, History, and Culture” adındaki bir derleme kitap aracılığıyla girmiştir. Bu kitapta konuyu ele kişi Susan Bassnett and Andre Lefevere'dir (Bassnett, Susan ve Lefevere, Andre, 1998, aktaran: Ar1, 2014, s.20.) Bu esere göre çeviri eğitimi kültürel araştırmalarla ilerleme sağlamasını ve sosyalbilimlerde kültürel dönüşümün varlığını dikkate alınması gerektiğinin yanısıra postmodernizmle olan ilişkiye atıf yapılmaktadır. Chesterman'ın görüşüne göre "çeviri pratiği” olgusu sosyal ve kültürel bakış açılarını içine alan bir özellik taşırken kültürel değerleri ve gelenekleri de hem etkilemekte hem de bu süreçten etkilenmektedir. Bu süreç zaman, kurum ve kültür anlamında sınırlılıkları çeviri süreci olarak aktarılmaktadır. 
Ülkeler arasında yaşanan çeviri süreçlerinde çevirisi yapılan dillerin hakimiyet alanlarının da gücü önemli bir rol üstlenmektedir. Buna göre hâkim konumda olan ülkelerin dilsel değerlerini çeviri eserler üzerinden ithal etme eğilimi göstermektedir. Hakimiyeti az olan ülkelerde ise bu ihraç süreçlerinin zayıf olduğu görülmektedir (A.g.e., s.96 aktaran: Arı, 2014, s.272). Çeviri süreçlerini etkileyen uluslararası kültürel farklllıklar üç farklı grupta toplanabilir. Bunları şekillendiren unsurların; 1) ülkeler arasındaki politik ilişkiler, 2) ekonomik ilişkilere, 3) kültürel dönüşümler üzerinden şekillenmekte olduğu görülmektedir. Bu süreçte emtianın girdiği dolaşıma metinler de dahil olmaktadır. Bu metinlerin dönüşümünde ortaya çıkan aktarım zinciri orijinalin üretildiği ve alındığı ülkenin kültürel yapısının yanı sıra ticari tarzına göre de şekillenmektedir (A.g.e., s.97 aktaran: Arı, 2014, s.273). Çevirinin ideolojik ve güç odaklarının yönlendirmesi altında da bulunan kültürel bir yapı biçiminde kültürleri dikkate değer biçimde yapılandırdığını aktaran Prunc bu noktaya dikkat çekmektedir (Bassnett, Susan ve Lefevere, 1998, Aktaran: E. Prunc, 2007a, aktaran: Ar1, 2014, s.274). Bu Özellikleri sayesinde çevirinin etrafindaki kültürel yapıları şekillendiren yapılandıran bir yapı şeklinde (Hermans, 1997, aktaran: E. Prunc, 2007, aktaran: Arı, 2014, s.274) çıkış noktası olan dilin kendisine ait olan kültürün dışarıya aktarılmasına katkıda bulunan ama aynı zamanda dış kültürün öğelerini de içeriye yansıtan bir yapısı bulunmaktadır (Bachmann 2004. 449-465. aktaran: Prunc, 2007'a, aktaran: Ar1, 2014, s.274). Çeviri eyleminin gerçekleşmesi esnasında kültürler arasında kuvvete ve hakimiyete dayalı bir irtibatın olduğu belirtilmektedir (Prunc, 2007a, s. 20 aktaran: Ar1, 2014, s.274). Prunc tarafindan, Bourdieu'nün alan kuramı çeviri sahası için dönüştürülmüş ve tarihi olarak güç ilişkilerinin idare edilmesinde bir hareket alanı olduğu belirtilmiştir (A.g.e., s.21 aktaran: Ar1, 2014, s.275). Alanın kendi içinde bulunan kuvvet sahalarının etkisi ile ilgili olarak sembolik sermayenin önemine değinilirken süreçte rol alanların sermaye açısından semboller üzerine odaklanmalarının önemine vurgu yapilmaktadır (A.g.e., s.23-24 aktaran: Ar1, 2014, s.275).

Wolf ise yapılan çevirilerin, tarihsel ve kültürel bir geçmişe atıf taşıdığı konusu üzerinde durmaktadır. Bu görüşten yola çıkan Bassnett de üzerinde çalışma yapılan bir nesnenin anlamlandırmasının tekrarlanarak kaynak ve hedef metin bağlamında dikkate alınmasının yerinde olacağını aktarmaktadır. Bu görüşler ışığında çeviri eyleminin geçirdiği dönüşümün etkilendiği güç durumu açı̆̆a çıkmaktadır. Nihai olarak çeviri eyleminin etrafındaki diğer etki unsurlarından sıyrılamayacağını belirtmek yerinde olacaktır (Wolf, 2007’a, s.132 aktaran: Arı, 2014, s.275).

\section{Kültür Aktarımı Olarak Çeviri}

Komisssarov çevirinin kültürlerarası etkileşimdeki rolüne değinerek; "Kültürlerarası iletişimde çeviri önemli bir araçtır. Bir kültürden diğerine çeviri kaynak dilin doğasında var olan yeni olguları ve fikirleri de beraberinde getirir. Erek dil okuyucularının kültürel ufuklarını genişletmek, başka insanların farklı geleneklere, sembollere ve inançlara sahip olabileceklerini konusunda uyarmak için bunlar bilinmeli ve sayg1 gösterilmelidir. Yine de çevirinin bu kültürel ve eğitici rolü çok fazla abartılmamalıdır” demektedir (Komissarov, s.100). Bugün itibariyle çeviri faaliyetinin bir bilim dalı olan çeviribilimin uygulama alanı içinde yer aldığı görülmektedir. Tarihsel süreçte çevirinin kültürlerarası aktarım aracı olası nedeniyle bilgi kültürlerarası alanda daha hızlı yayılma özelliği göstermektedir (Mutlu, 2019, s.34). Gentzler'e göre "kültürün hibrid doğası ve çevirinin dönüşümcü/dönüştürücü gücü, buna fazlasıyla imkân verir’”. Bu itibarla kültürle ilgili yapılan araştırmalar içerisinde çeviri dikkate değer bir yer almaktadır. Çeviri çalışmaları bu manada kültür çalışmaları ile ilgili olmaktadır. Kültürel yaklaşımlar çeviri çalışmalarını da etkilemektedir. Bu anlamda çeviri eyleminin kültürel faaliyetleri etkilediği ifade edilebilir. Esasında çeviri süreci bir dilsel olgu olarak değerlendirilebilir ancak doğası gereği kültürle iç içe olan çeviri dilsel bir öğe olmanın da ötesine geçebilmektedir. Dilsel bir öğe olmanın ötesine geçebilen çevir olgusu insan merkezli olması özelliğinden dolayı iletişim ve etkileşim sürecinin dikkate değer bir unsuru olarak ön plana çıkmaktadır. Bu bakış açısına göre kültür ve çeviri bir arada anılmakta her iki olgunun etki alanları içerisinde çeviribilimin araştırma sahası bulunmaktadır (Gentzler, 2017: xii). Dağll, 
kültürün çeviri ile olan aktarım ilişkisine değinirken; "Başka toplumları tanımada, o toplumlarla kendimizi karşılaştırdığımızda yalnızca bilgi aktarımının değil dünyayı değişik bir algılayış da gözlenmektedir. İşte bu değişik algılayış, kültür olgusudur. Başka bir deyişle her dil belli bir kültürün göstergeler dizisiyle belli uzlaşımlar, töreler, davranışlar, değer ölçüleriyle kısacası insan yaşamıyla iç içedir1 demektedir. (Dağlı, 1985, s.13). Simeoni ise çevirmenin habitusu olgusunu ele alırken süreci "çevirmenin bilinci" ya da "kültürel bilinç" olarak isimlendirmektedir. Bu sürecin birey, toplum ve kültürel tarih açsı1dan yaptığı etkiye de değinerek konuyu ele almaktadır. Aynı zamanda habitus olgusunun şahsi tecrübe ve sosyal hayatla ilgili alanlar arasında geçişi de içerdiği aktarılmaktadır (Simeoni, s. 177 aktaran: Arı, 2014, s.26). Hohman ise süreci kültürel semboller ve iletişim odaklı irdelerken M.Rey'in görüşünü aktarmaktadır. Bu aktarımda; "Fransız strüktüralist düşünce altında M.Rey'in (1979) kültürü, semboller sistemi olarak anlamasını değerli bir düşünce olarak buluyorum. Bu sistem, iletişimi ve karşlıklı etkileşimi yapılandırmakta ve bu sistem içerisinde kültür tanımı, kültürler arasındaki değişimde çatışma çıkartıcı bir görev üstlenmektedir" ifadelerini kullanmaktadır. Rey'in yaklaşım olarak benimsediği özelliklerin ise pedolojik formatla; "kültür ön koşullu stereotipilerin aşılması, kültürler arası açık bir diyaloga giriş, başkalarından deneyim kazanmak suretiyle ben-kimliğinin gelişimi, karşıt anlayışların uyandırılması, kültürel değişimlerle zenginleşme" biçiminde bir yol izlediği belirtilmektedir (Hohmann, 1983 s.4-8.). Kuran ise çeviri sürecinin farklı dilleri ve kültürleri etkilediğini aktarırken; "Çeviri yoluyla dillere farklı dil yapılarının, farklı fikirlerin, imge ve motiflerin, edebi yazın türü ve sanatlarının, farklı kültür unsurlarının girdiği, bunların ulusal yazınları etkilediği, karşılaştırmalı yazına temel hazırladığ1 bilinen bir gerçektir" ifadelerini kullanmaktadır (Kuran, 1995, s.7).Aeschylos'un Agamemnos (1816) eserinde, Wilhelm von Humboldt'un öncülük ettiği görüş aracilı̆̆ıyla (17671835) bir eserin "doğası gereği” çevrilemez olduğu fikrine varılmıştır (Störig 1969, s.71-76). Humboldt'un görüşüne göre, düşünme faaliyeti ana dile bağlı bir olgudur. Bu durumu açıklarken: "Dil aynı zamanda toplum tinlerinin somut görüntüsüdür; toplumların dilleri onların ruhlarıdır ve ruhları da dilleridir; ikisinin ne kadar özdeş olduğu tasarlanamaz bile" ifadelerini kullanmaktadır (Humboldt, 1949, s.60.). Kültürel aktarımın en önemli unsuru olan metin türleri bazen yönlendirici bir ulup alabilmektedir. Buna göre çevirmenlerin belirli amaçlar doğrultusunda görevlendirme ve iş olarak gördükleri bu süreci tamamlarken belirli kitleleri gözettikleri ve belirli işleve dönük olarak yaptıkları görülmektedir. Bu süreçte kaynak metin ve hedef metin arasında hedef ayrışması ve benzeşmesi yaşanan yerler olması da muhtemel olarak kabul edilmektedir. Bu açıdan metinler hazırlanırlarken değişik kültürler üzerinden belirli amaçlar ve kitle için hazırlandıkları anlaşılmaktadır. Bu konunun anlaşılması için metin türlerinin farklılıklarının irdelenmesi yerinde olacaktır. K. Reiss bu noktada tüm metinlerin temel hedefinden bahsetmektedir. Buna göre metinler genel itibarıyla bilgi verme özelliği taşımaktadır. Bu metinlerin sahip olduğu üç ayrı tip metinden bahsetmek bu noktada dikkate değer bir önem taşımaktadır. İlk olarak bilgi veren (informatif) metin türü, ikinci olarak ifade taşıyan (edebi) metin türü (expressif), üçüncü olarak ise reklam metinleri, dinsel ve siyasal metinler gibi yönlendirici (tahrik) metin türü (operatif) gibi metin türlerine dikkat çekilmektedir. (Reiss, 1995, s.12-17). Muharrem Tosun bu noktada Schadewalt (1973:235) Romalıların içinde bukunduğu toplumun çeviriye gösterdiği yoğun ilgiliye dikkat çekerek çevirinin eğitime yaptı̆̆ı eğitimin yoğunluğunu ele almaktadır. Romalıların çevir sanatında mucit olacak kadar mahir oldukları belirtilirken, bu maharetlerinin Yunan eserlerinin Latinceye aktarllırken kendi kültürlerini de dikkate alarak fazlasıyla sergilendiğini belirtmektedir (Vermeer,1992:192-195 aktaran: Tosun, s.55-56.). Königs işlevsel bakış açısını dikkate alırken Vermeer ve Maenttaeri'nin kültür odaklı bir kuram ortaya koymalarını da esas almaktadır. Bu kuramcıların çeviri ile ilgili olarak salt dilsel olgu değerlendirmesi yapmak yerine bilakis kültürel bir genişleme olarak değerlendirdikleri görülmektedir. Bu kuramcılar dilsel faaliyeti kültürler üzerinden yapılan bir faaliyet olarak ele almakta ve bunun da iki kültürlü olması gerektiğini vurgulamaktadırlar. Königs bu düşüncelerin Vermeer (1986) ve Snell-Hornby (1988) gibi uzmanlar tarafindan ortaya atıldığını aktarmaktadır. 
Bu noktada çevirmenin hem kaynak metin hem de hedef metin süreçlerinde yapılan çeviri faaliyeti için gerekli olacak başarının kültürel bilgi sayesinde başarılabileceğini aktarılmaktadır. Kültürün, her dilsel bilginin mecburen içinden geçmek mecburiyeti taşınan bir filtre görevi olduğu belirtilmektedir (Tosun, 2002, s.66-67). Çeviri olgusu çevirmenin kişisel faaliyeti olmasının yanında toplumsal faaliyet olarak da çevirmenin habitusunu oluşturmaktadır. Ayrıca, çevrilecek olan metin kültürel sembollerin katılımı ile daha da anlamlı hale gelecektir. Kültürel sembollerin çeviri sürecine dahli sayesinde çevirisi yapılan metin anlaşılma ve yorumlanma yolunda önemli bir mesafe kat etmektedir. Kültürel sembollerin odak noktasında yer almasıyla çeviriler görecelik açıdan zayıflamakta ve çevirmenlerin sürece olan katkıları güçlü ve anlaşlır hale gelmektedir (Arı, 2016, s.21.). Şirin ise kültürün maddi ve manevi öğelerini ele alarak bunların farklılaşmasını açıklamaktadır. Buna göre; "İnsanlar ilkel hayattan başlayarak, günümüze kadar gelebilmek için birçok dönemler geçirmişlerdir. Bu süreç içinde meydana getirdikleri her şey onların kültür ürünleridir. Yemek içmek için yaptıkları kaplar, giyinmek için ürettikleri elbiseler yaptıkları aletler, yaşamak için kurdukları şehir ve köyler onların maddî kültürünü; din, düşünce, edebiyat, tarih alanındaki eserleri de manevî kültürünü oluşturur" ifadelerini kullanmaktadır. (Şirin, 2002, s.299) Kültürü ele alan Arı kültürün bilgi aktarımı sürecine göre sabit ve değişken olma özelliği olduğunu belirtmektedir. Kültür içinde yaşanan bu değişkenlik nedeniyle para, -dia ve -idio kültürlerin bu süreci tasnif ettiği aktarılmaktadır. Kültürün bu şekilde tasnif edilmesinin kültürü kibritlik çerçevesinin dışında zengin ve dinamik bir sistem olarak ifade ettiği belirtilmektedir. Bu gerçek ise kültürlerin birbirinden etkilenme etkileme süreçleri yaşamasının doğallı̆̆ına yapılan bir atıf olarak ortaya çıkmaktadır. Kültür esaslı yaşanan değişim sürecinin ise kültürün güçlenmesine yol açacağ1 belirtilmektedir. (Arı, 2016, s.27.). Erek kültür dizgesi edebi sahada çoğul dizgeyi çevirilerin bir parçası biçiminde sürece dahil ederken bu olgunun çoğul dizgeye olan katkısı sayesinde Toury ve EvenZohar bu süreci erek kültürel ve edebi sistemde oluşan bir eksikliğin giderilmesine katk1 sunduğu biçimde belirtmektedir. Yücel ise eksik giderme veya boşluk doldurma olarak adlandırılan bu sürecin farklı düzlem ve zamanda gerçekleştiğini belirtmektedir. Sosyal, kültürel, ekonomik, siyasal, askeri, tarihsel sosyokültürel unsurların ise erek okuyucu kitlesinin dikkatinin yönlendirilmesi için dikkate değer role sahip olduğu aktarılmaktadır (Yücel, 2007, s.160.). Kültürbilimin sembolik değerlerinin katk1 sunduğu rolün açılı̆̆a kavuşturulmasında Bourdieu'nun rolü olduğu belirtilmektedir. Çeviribilim alanının toplumsal ve kültürel açıdan Bourdieu tarafindan incelenmesi sonucunda kültürün çeviri ile olan alakasına dair önemli katkılar sunulduğu görülmektedir (Arı, 2016, s.82-83.). Çeviribilim açısından bakıldığında kültürel semboller üzerinden yapılan aktarımda yöntem, strateji ve bilinç oluşturulması esnasında çevirmen; metin, çeviri eğitimi ve çeviri eleştirisi üzerinden sembolleri esas alan bir süreçte karar aşamasında kalmaktadır (Arı, 2016, s.82-83.). Şevik ise kültürel bir aktarım aracı olarak çevirinin rolüne değinerek; "Çevirinin bir anlamda, bir ülkeye ait olan kültürel öğelerin aktarımı olduğu göz önüne alındığında, bu öğelerin aktarım sonucunda erek dil ve kültürde, kaynak kültürde sahip olduğu aynı özelliklere veya aynı etkiye sahip olması beklenmediği bilinmektedir” görüşlerine yer vermektedir Şevik, Nesrin, 2020, 239).

\section{Türkiye'de Çeviri Yoluyla Kültür Aktarım Çabası}

Türkiye tarihindeki çeviri yönetiminden bu noktada bahsetmek yerinde olacaktır. Şimşek'e göre; "Türkiye tarihindeki çeviri yöntemi bir yabancılaşmadır. Fakat bu yabancılaştırma yöntemi Schleiermacher'in yöntemine uygun bir yabancılaşma değildir. Yerli kültürün kendine yabanc1 kavram ve düşünceyi yabancı kültürden edilmesi değil, yabancı kültürün de yabancılaştırılıp, bir başka amaç doğrultusunda farklı ve eksik sunulduğu bir yabancılaştırmadır" şeklinde aktarılmaktadır. Ayrıca Şimşek çeviri üzerinden melez bir kültür oluşturulması konusuna da değinerek konuyu; "Çeviri yöntemi olarak kaynak kültürde ve erek kültürde aynı şekilde yabanc1 bir strateji söz konusudur. Amaç yabancı bir kültürün tüm yönleri ile alınması da olmayıp hedeflenen ideolojiye uygun yanlarının başka parçalarla birleştirilip melez bir kültür üretmek 
olmuştur. Bir üçüncü kültür düzlemi oluşturulup yerli kültür boşaltılarak, yabancı kültürel öğeler ile doldurmaktadır" biçiminde özetlemektedir (Şimşek, 2017, s.160).

Buradan hareketle hiçbir kültürün tam olarak saf olmadığı anlaşılmaktadır. Aynı zamanda kültürler kendi milli kimliklerinin de ötesine geçebilmektedir. Kültürü oluşturan önemli unsurlar olan dilsel ve dinsel olgular ulusal sınırlar içine sığmayacak kadar evrensel hal alabilmekte ve bunun da ötesinde geçmiş ve gelecek arasında öenmli bir unsur olarak görev yapabilmektedir. Bu nedenle bir ulusun içerisinde birçok kültürün farklı anlayış kalıpları da kendisine yer bulabilmektedir. Bu kültürel ve fikri gruplaşmaların ise kendi içlerinde de alt gruplara bölündüğü ve kendi varlıklarını anlamlandırmak adına ulusal sınırların ötesinde anlayışlarına yakın hissettikleri kültürel unsurları tanıma yolunu seçtikleri görülmektedir. Bu tanıma ve tanınma sürecinde ise ortaya çıkan dil bariyerinin çeviri faliyetleri ile aşılma yolu seçildiği görülmektedir. Bu noktada örnek verilebilecek bir çalışma süreci ise 1960 sonrasında, İslam dünyasından yapilan tercüme çalışmaları olabilir. Birçok düşünce yapısının kendi görüşüne dayanak veya destek bulmak için çevir faaliyetlerini yoğunlaştırdığı bu dönemlerde İslamcı düşünceye sahip grupların da bu süreçten etkilendiği gözlenmektedir. Bu konuyu ele alan Bulut; "60’lı ylllardan itibaren, milliyetçimukaddesatç1-muhafazakâr-devletçi İslâm anlayışlarından kendisini ayrıştırmaya çalışan, bağımsız, eleştirel, reddiyeci ve devrimci olma istek ve iddiasına sahip bir Müslüman kimliğinin inşasına dönük çabalar, dönemin bilgi birikimini de göz önünde tutacak olursak, daha çok tercüme eserler aracıllı̆ı̆la amacına ulaşmaya çalışmıştır. Bu amaca ulaşmak için de, Türkiye İslâmcıllŭ̆, hem yerli Batıc1 elitlerle, hem sömürgeci ve pozitivist kimliğe sahip Batı medeniyetiyle, hem de Türkiye'deki hâkim dinî anlayışlarla hesaplaşma ihtiyacı hissetmiştir" ifadeleriyle konuyu özetlemektedir. Bu dönemde yapılan çevir çalışmalarının geçtiği süreçleri de ele alan Bulut; "Dönemin az sayıdaki telif, çok sayıdaki tercüme eserlerinde söz konusu hesaplaşmanın bütün boyutlarını görmek mümkündür. Mevcut hâkim anlayışlardan farklı bir kimlik oluşturma sürecinin nasıl bir seyir izlediği, hangi safhalardan geçtiği, ortaya ne türden bir kimlik çıtığı ise ayrı bir çalışmanın konusudur" ifadesini kullanmaktadır (Bulut, 2013, s.362.).

\section{Sonuç}

Kuramsal bakış açısıyla yapılan çalışmaların gösterdiği üzere H. J. Vermeer’in bahsini ettiği çevirideki kültür kavramı neticesinde 1980’li yılların ikinci yarısından sonra çeviriden bir kültür aktarımı süreci unsuru olarak bahsedilmesine yol açmıstır. Günümüzde ise çeviribilim alanında yürütülen çalışmalar bu alanda kültürün sağladığı rehberliğin her zaman canlı bir biçimde sürdügünü göstermektedir. Bunun da ötesinde devrin yenilenen ihtiyaç ve beklentileri üzerine sunulan öneriler bu sürecin güncel kalmasına ve bu sahanın ilerlemesine yol açmaktadır. "Sonuç olarak, çevirinin kültürel bir eylem olması ve parçası olduğu kültürün bireyleri tarafindan icra edilmesi bir iletişim aracı olan çevirinin konumunu daha etkin ve anlamlı kılmaktadır. Çünkü sosyalleşme bireyler arası etkileşimi tetiklemekte ve bu etkileşim iletişime olan ihtiyacı açı̆ga çıkarmaktadır. Oxford Üniversitesi profesörlerinden dilbilimci Roy Harris'in açlış dersinde dile getirmiş olduğu, iletişim dilden önce gelir iddiası (1978), iletişim ihtiyacının önceliğine olduğu kadar dilin daha uzun bir sürecin uzantısı olduğuna bir göndermedir. Bu anlamda, Doris Bachman-Medick, kültürler arası çeviriyi diller arası çevirinin ötesinde görmekte ve çevirinin bağlam ve işleve göre anlam kazanan kültürler arası bir iletişim aracı olduğuna işaret etmektedir (1997)". (Gezer, Can, 2019, 362). Bu bağlamda çeviribilim alanında yapılan kuramsal ve uygulama çalışmaları nihai olarak kültür kavramı bağlamında değerlendirilmektedir. Bu durum toplumun tarihi, kültürel ve beşerî atılımı sürecinde elde ettiği maddi ve manevi değerlerin bir araya gelmesiyle oluşan bir süreçtir. $\mathrm{Bu}$ süreç ise çeviri faaliyetleri ve dilden ayrı bir biçimde değerlendirilmemeli ve düşünülmemelidir. 


\section{Kaynakça}

Arı, Sevinç. (2016). Çeviri ve Kültürel Semboller, Değişim Yayınları, İstanbul.

Aksoy, Berrin. (2000). Kültür Odaklı Çeviri ve Çevirmen,

http://turkoloji.cu.edu.tr/DILBILIM/aksoy kultur ceviri.pdf, Erişim Tarihi:10.11.2020

Ateşman, Ender. (2001). Kültürel Farklardan Kaynaklanan Çeviri Sorunları ve Çözüm Önerileri, Hacettepe Üniversitesi Edebiyat Fakültesi Dergisi Cilt: 18, Sayı: 2, ss. 29-35 https://dergipark.org.tr/tr/pub/huefd/issue/41190/497514, Erişim Tarihi: 22.11.2020

Bachmann-Medick, Doris. (2004). "Ubersetzung als Medium interkultureller Kommunikation und Auseinandersetzung". İn Handbuch der Kulturwissenschaften. Band 2. Para- digmen und Disziplinen, F. Jaeger, B. Liebsch, J. Ruşen and J. Straub. Stuttgart and VVeimar: Metzler. 449-465. Aktaran: Prunc, (2007a), 20 aktaran: Ar1, 2014

Bassnett, Susan ve Lefevere, Andre. (1998). Constructing Cultures. Essays on Literary Translation. Clevedon: Multilingual Matters. Aktaran (Esperançadan): Bielsa Mialet aktaran: Arr, 2014.

Bassnett, Susan, "When is a Translation not a Translation?" Constructing Cultures: Essays on Literary Translation, Ed. Susan Bassnett and André Lefevere. Clevedon, Cromwell Press., 1998, S.25-40.

Bourdieu, Pierre. Die Feinen Unterschiede, Kritik der Gesellschaftlichen Urteilskraft - (İnce Ayrımlar, Toplumsal Yarg1 Gücünün Eleştirisi) (Çev. B. Schwibs ve A. Russer), Frankfurt am Main: Suhrkamp.

Bulut, Yücel. (2013). Türkiye'de İslâmcılık Düşüncesi ve Hareketi Sempozyum Tebliğleri Zeytinburnu Belediyesi Kültür Yayınları Kitap No: 31, Editör İsmail Kara Asım Öz, 1. Bask1 İstanbul.

Chesterman A., ve Williams J. (2002). The map: a beginner's guide to doing research in translation studies. Manchester: St. Jerome. ISBN 1-900650-54-1 (pbk).

Chesterman, A. (2007). Bridge concepts in translation sociology. M. Wolf ve A. Fukari (Ed.). Constructing a Sociology of Translation içinde. Amsterdam: John Benjamins, s. 173 aktaran: Ar1, 2014.

Cömert, Bedrettin. Kuramsal Açıdan Çeviri Sorunu. TDK. Çeviri Özel Sayısı 322, Ankara 1978 sf.26

Dağl1, Yasemin. (1985) Georg Büchner'in "Woyzeck" adlı Eseri ile Türkçe Çevirisinin Syntax, Semantik ve Pragmatik açılardan Karşılaştırılması. Lisans Bitirme Tezi, Konya.

Geertz, Clifford. (2010). Kültürlerin Yorumlanması, çev. Hakan Gür, Dost Kitabevi Yayınları, Ankara.

Gentzler, E. (2017). Translation and rewriting in the age of post- translation studies: new perspectives in translation and interpreting studies. Routledge.

Erdoğan, İrfan. (2005). İletişsimi Anlamak. Erk Yayınları, Ankara.

Gezer G. ve Can M.Z. (2019). Kültürü çevirmek: Kültür aktarımı kapsamında çeviri, RumeliDE Dil ve Edebiyat Araştırmaları Dergisi 2019.17 (Aralık), https://dergipark.org.tr/tr/download/article-file/878104, ss.355-370.

Giddens, A. (2005). Sosyoloji, Çev., Cemal Güzel, Ayraç Yayınevi, Ankara.

Haviland. A. ve L. Prinss, v.d., (2008), Kültürel Antropoloji, Çev. İnan Deniz Erguvan Sarığlu, Kaknüs, İstanbul.

Hermans, T. (1996). "Norms and the Determinations of Translation. A Theoretical Framevvork". dn: Roman Alvarez + M. Carmen-Africa Vidal (eds.) Translation, Power, Subversion. Clevedon ete.: Multilingual Matters Ltd. Aktaran: Klaus Kaindi, (1999) aktaran: Ar1, 2014

Hermans, Theo. (1997).. "Translation as institution". In Translation as Intercultural Communication. Selected Papersfrom the EST Congress Prague 1995, M. Snell-Hornby, Z. Jettmarova and K. Kaindi (eds). Amsterdam and Philadelphia: John Benjamins. 3-20. Aktaran: E. Prunc, (2007a), 20 aktaran: Ar1, 2014 
Hohmann, M. (1983). Interkulture Verziehung- Versucheiner Bestandsaufhahme. in:Auslânderkinder in Schuleund Kindergarten. (4), 4-8.

Holz-Maenttaeri, (1984) .Justa. Translatorisches Handeln, Theorie und Methode, Helsinki: Suomalainen Tiedeakatemia,

Holmes, James. (1988)."The Name \& Nature of Translation Studies", Translated Papers on Literary Translation and Translation Studies, Amsterdam: Rodopi,

Hönig, G. Hans (1982). Strategie der Übersetzung, (Ein Lehr-und Arbeitsbuch) Tübingen: Gunter Narr Verlag,.

Humboldt, Wilhelm von. (1949).Über die Verschiedenheit des menschlichen Sprachbaues und ihren Einfluss auf die geistige Entwicklung des Menschengeschlechts, Darmstadt: Mit einem Nachwort hrsg. Von. H. Nette,

Journet, Nicolas. (2009). "Kültür Nedir?”, Evrenselden Özele Kültür, çev. Yümni Sezen, İstanbul.

Kaindi, K. (1999). Übersetzungswissenschaft im interdisziplinaren Dialog. Tübingen: Stauffenburg Verlag. s. 124 aktaran: Arr, 2014

Komissarov, Vilen. N. Çeviride Dil ve Kültür: Paydaş mı Yoksa Rakip mi? Çev: Mehmet İLİ, M. İLI / Karatekin Edebiyat Fakültesi Dergisi (KAREFAD) 4(1): 91-102, https://dergipark.org.tr/tr/pub/karefad/issue/19205/204185, Erişim Tarihi: 15.03.2021

Kuran, Nedret. (1995). Çağdaş Alman Çeviribilimcilerinin Yaklaşımları, Çeviri ve Çeviri Kuramı Üstüne Söylemler, İstanbul

Maenttaeri, Holz. (1984). Translatorisches Handeln, Suomalainen Tiedeakatemia, Helsinki.

Mounin, Georges. (1963), Les Problèmes Théoriques de la Traduction. Paris:. Ed. Gallimard.

Mutlu, Sıla. (2019). Yayınlanmamış Doktora Tezi Türkiye'deki Akademik Çeviri Eğitiminin Çeviri Kuramlarıyla Bağlantısı ve Pratikteki İşleyişi, Sakarya,.

Reis, Katherina. (1995). "Der Texttypund Übersetzungsmethode", Julius GroosVerlag, Heidelberg, 1995.

Stolze, Radegundis. Übersetzungstheorien, Tübingen: Eine Einführung, 1994/2001.

Störig, Hans Joachim. (1963). Das Problem des Übersetzens, Darmstadt: Wissenschaftliche Buchgesellschaft.

Simeoni, Daniel. (1998). "The Pivotal Status of the Translator's Habitus". Target 10 (1). Aktaran: Andrevv Chestermar» (2007) aktaran: Ar1, 2014

Strauss, Claude Levi. (2012). Yapısal Antropoloji, çev. Adnan Kahiloğulları, İmge, Ankara.

Şevik, Nesrin. (2020). (Kitap İncelemesi) “Kültür Aktarımı Kuramının Eleștirisi-Türkiye'nin Medenileşme Sürecinde Çevirinin Rolü”, Karamanoğlu Mehmetbey Üniversitesi Uluslararası Filoloji ve Çeviribilim Dergisi, C.2/2, s.232-240.

Şimşek, Fatih. (2017). Kültür Aktarımı Kuramının Eleştirisi, Sakarya Kitabevi, Sakarya.

Şirin, Veli. (2002). Anahtarlarıyla Siyasî ve Kültürel Osmanlı Tarihi, Marifet Yayınları.

Hall, Stuart.(1982). "Culture and the State", Open University, The State and Popular Culture.

Tosun, Muharrem. (2002). "Erek Odaklı Çeviribilim Kuramlarının Kültürel Aktarıma Bakışı ve Çeviribilimde Pardigma Değişimi”, Edebi Çeviri ve Kültür Transferi, Ege Alman Dili ve Edebiyat1 Araştırmaları Dergisi, İzmir. Königs, 1990:112; Tosun, 2002:66-67

Toury, Gideon. In Search of a Theory of Translation, Poerter Instituts for Potics and Semiotics, Tel Aviv, 1980

Vermeer, Hans J. (1992). Skizzen zu einer Geschichte der Translation: Altenglisch, Altsächsisch, Alt- und Frühmittelhochdeutsch Literaturverzeichnis und Register für Band 6.1 und 6.2 Frankfurt: IKO - Verlag für Interkulturelle Kommunikation.

Vermeer, H. J. (1996). A Skopos Theory of Translation (Some Arguments for and against). TextContext: Heidelberg.

Yücel, Faruk. (2007). Tarihsel ve Kuramsal Açıdan Çeviri Edimi, Dost Kitabevi, Ankara. 

doi:10.14687/jhs.v18i4.6213

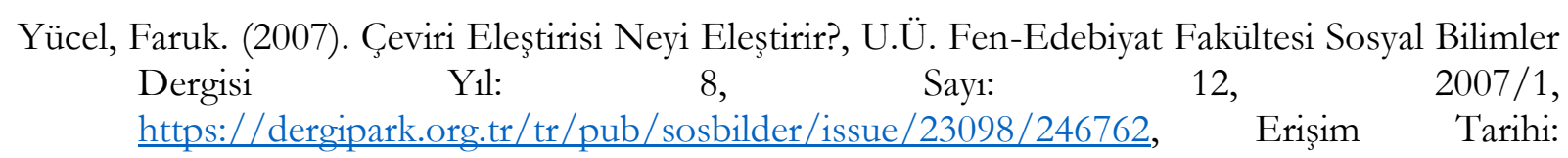
12.02.2021

\section{Extended English Summary}

Culture is a phenomenon to effect the social habitus of the people in a developing manner. To examine the situation to get better results in the scope of translation science can get better result if focused on different dimensions. In such cases the effect of tranlations on culture can turn into a must type of result for the generating the future of a culture. But at first it must be understood that the importance of a culture and the meaning as well. As soon as it is understood to comprehend transfer of a cultural activity or heritage can be easily understood regarding the translation studies. Otherwise the cultural transfer can not be defined as it is fucused to be. The words of culture and civilization should also examined together to analyse the process properly. Thus, in the first part the culture has been discussed in the place given. Essentially, ideas, human products, practices, and institutions come from a system. Through the transfer of culture, which can be defined as the transfer of items that pass from one culture to another are subject to a dynamic process. In this respect, culture would be an appropriate determination to say that there is a dynamic process for the transfer of the process of creativity. In the second part the tranlation issue has been evaluated on the different examinations of scholars to be understood better. Translation activities, which have important contributions to the development of culture and science, are examined by different scientists from various perspectives, both structurally and formally. The quality of the translation products that will be put forward will be able to be fully evaluated if the studies revealed by the translation are primarily dealt with from a systematic point of view. The production to be provided by these systems, which are also important in terms of carrying a cultural value, also includes a paradigm in itself. In the third part the tranlstions and culture issue has been evaluated to be understood better. In this respect the translation activity develops as a process that takes place between lower and upper cultures or within a culture, it is seen that it plays a bridge role between the past and the future between languages. At the same time, it is stated that since culture has a future-oriented aspect, it is expected to be "transferred to the present day as a work for humanity and simultaneously to ensure transitivity between national cultures". In the fourth part translation has been evaluated as a cultural transfer. According to this evaluation it can be stated that the act of translation affects cultural activities. In fact, the translation process can be considered as a linguistic phenomenon, but translation, which is intertwined with culture by its nature, can go beyond being a linguistic element. The phenomenon of translation, which can go beyond being a linguistic element, stands out as a remarkable element of the communication and interaction process due to its human-centered feature. In the fifth part the efforts to transfer culture through translation in Turkey ahs been discussed. In this regard an exemplary work process at this point may be the translation studies made from the Islamic world after 1960. It is observed that groups with Islamist ideas were also affected by this process in these periods when many thought groups intensified their translation activities to find support or support for their own views. Addressing this issue, in 60s, efforts to build a Muslim identity that tries to differentiate itself from the nationalist-holy-conservativestatist understandings of Islam, and that has the will and claim of being an independent, critical, rejectionist and revolutionary, can be seen more and more if we take into account the knowledge of the period. He tried to reach his goal through translated works. In order to achieve this goal, Turkish Islamism felt the need to come to terms with both the indigenous Westernist elites, the Western civilization with a colonial and positivist identity, and the dominant religious understandings in Turkey. In this respect following the discussions on this topic it is understood that the translation and culture can turn and effect cultural changes. 
As it is accepted that translation may not seem like a system or a closed system because of the act of the translator. Translation may turn into a closed system because of the phenomenon of translation and its special integration to structural social system. Since social system reproduces itself communicatively over the years and in different societies, in a sense, a new paradigm is mentioned in the theory of translation action, which leaves behind the individuality of the translation and the individual role of the translator. In this paradigm, the act of translation refers to the autopoietic system of translation. This paradigm may not the temporary decisions of the translator, but the features that are immutable in the temporary and similar to the system and that will evaluate that translation process as similar in the general translation system. Within the cultural changes, translation may also have a feature to change or to be changed by the effectively and systematically focused process or effecting agents. The true definition of the cultural effect of the translation within this process may reveal during the translation phase. 